\title{
Vast database offers vision of biodiversity
}

[PARIS] The Organization for Economic Cooperation and Development (OECD) last week approved plans aimed at creating the world's largest biodiversity databank. The Global Biodiversity Information Facility (GBIF) will be launched later this year.

Science ministers from the OECD's 29 member states also decided to redirect its Megascience Forum, a group set up seven years ago to coordinate large scientific projects among member countries. Now called the Global Science Forum, it will emphasize international cooperation to develop global science infrastructures of any dimension.

GBIF is to be launched by an interim steering committee with members from ten countries, with a permanent secretariat to be formed by mid-2000. It will knit together existing databases on biodiversity, to serve as a one-stop information resource. The multimillion dollar project will largely be funded by existing national programmes, such as the effort by the US National Science Foundation (NSF) to digitize natural history data.

Some databases that will contribute to GBIF are already running on websites, including Species 2000, a UK project aimed at indexing all species names. One of GBIF's most important tasks will be to create a comprehensive list of species names, solving problems caused by double references to organisms or misnamed species.

"Sometimes an inappropriate name is used and we find out we've been protecting the wrong organism," says James Edwards, deputy assistant director of the NSF's directorate for biological sciences and chairman
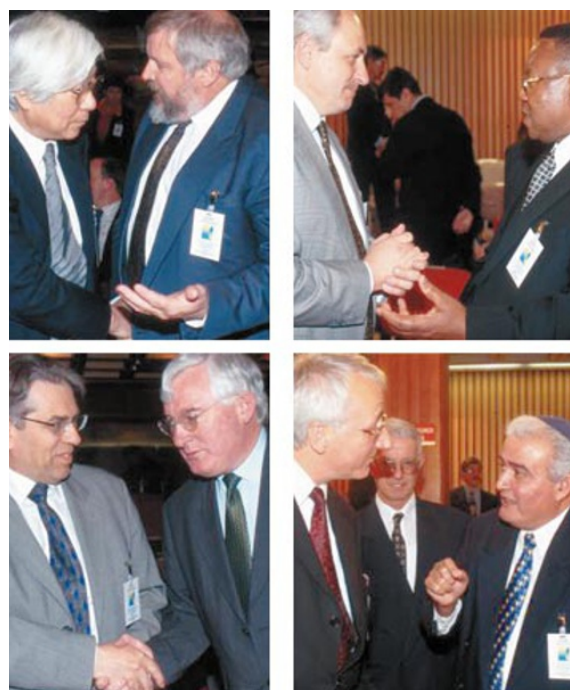

Giving science a hand, clockwise from top left: ministers from Japan, Norway, Russia, South Africa, Israel, Germany, Ireland and Iceland.

of the Megascience Forum bioinformation working group. "Or two countries use different names, so they can't communicate about an endangered species."

GBIF, which is intended to go online in three to four years, will contain scores of databases - including geospatial, chemical, molecular and genetic collections - plus a catalogue of names of known organisms, digitization of natural history data, literature resources, and a bank dedicated to the discovery of new species. It will also include training and outreach programmes to help scientists to use it. Specialists say that GBIF will change the study of biodiversity.

"Because of distance, it is humanly impossible to get a real vision of biodiversity. A few years down the road we will think 'How could we talk about biodiversity when we couldn't even see it?' "' says Frank Bisby, professor of botany at the University of Reading in Britain and chairman of Species 2000.

The idea for GBIF originated three years ago in the Megascience Forum. The new Global Science Forum will tackle such issues as the rivalry between the US Superconducting Collider and Europe's proposed Large Hadron Collider. But it will also consider smaller projects, in the hope of bringing policy-makers and scientists together to resolve international issues.

"We thought, "Why not extend the mandate so that virtually every project in science can be considered?'," says Michael Oborne, deputy director of the OECD's science, technology and industry directorate. "This will be a significant tool for the scientific community worldwide."

Particle physics and next-generation accelerators could emerge as a hot topic, says Oborne, as could nuclear waste disposal, which the Megascience Forum looked at without drawing up any solutions.

Last week's meeting also decided to form a year-long task force on radioastronomy to sort out conflicts between telecommunications companies and radioastronomers over sharing wavebands (see Nature 399, 513; 1999). Radioastronomers have been fighting to prevent mobile phones polluting their designated wavebands. Heather McCabe

\section{US 'wastes vital time' as climate-change minority sows confusion}

[WASHINGTON] Scientists have accused the US Congress of ignoring solid data on climate change, wasting precious time that should be used to counter the effects of humangenerated greenhouse gases.

The group of 57 scientists from 24 states, organized by the Union of Concerned Scientists (UCS), told a press conference this week that the effects of global climate change could be severe for the United States.

They urged Congress to adopt policies to improve energy efficiency and encourage the use of renewable energy. They said Congress should not be distracted by the "contrarian" views of a handful of scientists who dispute what they described as a mainstream scientific consensus on climate change.

“The mainstream scientific community's voices aren't being heard in Congress," says congressman Rush Holt (Democrat, New Jersey), the former director of the Princeton Plasma Physics Laboratory, who took part in the press conference. "It doesn't make sense to say we need to give equal time to the one or two per cent of scientists who are saying something totally different from the scientific consensus."

The production and consumption of energy is "the number one insult to our globe”, says Holt. “[But] I don't think one member out of 50 in Congress would think of it that way." People find it hard to grasp the urgency of an issue mainly reported in complex statistical formats, he says.

Patrick Michaels, of the University of Virginia in Charlottesville, challenges the UCS view. "The bottom line is that the climate models that served as the basis for most of this concern were wrong," says Michaels. "The planet will warm, but not as much as it was feared." He says that government efforts to promote renewable energy and energy efficiency are not needed in a market system in which they will evolve anyway. "Doing very little about this is the best way to solve the problem."
Michaels' views are typical of "minority viewpoints that haven't been adequately peer-reviewed" and that confuse Congress, says Walter Oechel, a professor of biology and director of the Global Change Research Group at San Diego State University. Oechel contributed to the 1995 report of the Intergovernmental Panel on Climate Change, a United Nations-sponsored group of 2,500 scientists who found that human activity was raising atmospheric temperatures.

Last November, the United States signed the Kyoto Protocol, stating a commitment to reduce carbon emissions to seven per cent below 1990 levels between 2008 and 2012. But President Bill Clinton has not submitted the treaty to the Senate for ratification. He says he first wants assurances of meaningful participation from key developing countries such as China and India, and negotiations to be concluded on provisions for emissions trading. These are not expected to be complete until 2001.
Meredith Wadman 